\title{
Enhancement of human ACAT1 gene expression to promote the macrophage- derived foam cell formation by dexamethasone
}

\author{
Li YANG ${ }^{1}$, Jin Bo YANG ${ }^{1}$, Jia CHEN ${ }^{1}$, Guang Yao YU ${ }^{1}$, Pei ZHOU ${ }^{1}$, Lei LEI ${ }^{1}$, Zhen Zhen WANG ${ }^{1}$, \\ Catherine CY CHANG, XinYing YANG ${ }^{1}$, Ta Yuan $\mathrm{CHANG}^{2, *}$, Bo Liang $\mathrm{LI}^{1, *}$
}

${ }^{I}$ State Key Laboratory of Molecular Biology, Institute of Biochemistry and Cell Biology, Shanghai Institutes for Biological Sciences, Chinese Academy of Sciences, Graduate School of the Chinese Academy of Sciences, 320 Yueyang Road Shanghai 200031, China.

${ }^{2}$ Department of Biochemistry, Dartmouth Medical School, Hanover, NH 03756; USA.

\begin{abstract}
In macrophages, the accumulation of cholesteryl esters synthesized by the activated acyl-coenzyme A:cholesterol acyltransferase-1 (ACAT1) results in the foam cell formation, a hallmark of early atherosclerotic lesions. In this study, with the treatment of a glucocorticoid hormone dexamethasone (Dex), lipid staining results clearly showed the large accumulation of lipid droplets containing cholesteryl esters in THP-1-derived macrophages exposed to lower concentration of the oxidized low-density lipoprotein (ox-LDL). More notably, when treated together with specific anti-ACAT inhibitors, the abundant cholesteryl ester accumulation was markedly diminished in THP-1-derived macrophages, confirming that ACAT is the key enzyme responsible for intracellular cholesteryl ester synthesis. RT-PCR and Western blot results indicated that Dex caused up-regulation of human ACAT1 expression at both the mRNA and protein levels in THP-1 and THP-1-derived macrophages. The luciferase activity assay demonstrated that Dex could enhance the activity of human ACAT1 gene P1 promoter, a major factor leading to the ACAT1 activation, in a cell-specific manner. Further experimental evidences showed that a glucocorticoid response element (GRE) located within human ACAT1 gene P1 promoter to response to the elevation of human ACAT1 gene expression by Dex could be functionally bound with glucocorticoid receptor (GR) proteins. These data supported the hypothesis that the clinical treatment with Dex, which increased the incidence of atherosclerosis, may in part due to enhancing the ACAT1 expression to promote the accumulation of cholesteryl esters during the macrophage-derived foam cell formation, an early stage of atherosclerosis.
\end{abstract}

Keywords: ACAT, dexamethasone, macrophage, cholesteryl ester, gene promoter.

\section{INTRODUCTION}

Atherosclerosis and its complications, coronary heart disease and stroke, constitute the most common cause of mortality, and become the pre-eminent health problem worldwide. In broad outline, atherosclerosis could be considered to be a chronic inflammation process, which could ultimately lead to the development of complex lesions or

\footnotetext{
"Co-Corresponding authors: Ta Yuan CHANG

Tel: (603)-650-1622, Fax: (603)-650-1483

E-mail: Ta.Yuan.Chang@dartmouth.edu;

and Bo Liang LI

Tel: (86)-21-5492-1278, Fax: (86)-21-5492-1279

E-mail: blli@sibs.ac.cn
}

Abbreviations: ACAT, acyl-coenzyme A:cholesterol acyltransferase FBS, fetal bovine serum; kb, kilobase(s); bp, base pair(s); PBS, phosphate-buffered saline; PCR, polymerase chain reaction; PAGE, polyacrylamide gel electrophoresis. plaques, protruding into the arterial lumen $[1,2]$. Although the recruitment of monocytes to the arterial wall and their subsequent differentiation into macrophages might initially serve a protective function by removing cytotoxic and proinflammatory particles of the cell-oxidized low-density lipoprotein (ox-LDL) or apoptotic cells, progressive accumulation of macrophages and their uptake of lipoprotein-derived cholesterol ultimately led to development of atherosclerotic lesions $[1,2]$. The development of macrophage-derived foam cells that contain massive amounts of cholesteryl esters becomes a hallmark of early stage of atherosclerotic lesions $[2,3]$.

Acyl-coenzyme A:cholesterol acyltransferase (ACAT) is the key and exclusive intracellular enzyme catalyzing the formation of cholesteryl esters [3]. Two ACAT genes have been identified in mammals (named acat1 and acat2), and ACAT 1 shows the major ACAT activity in macrophages 
$[4,5]$ for storing cholesteryl esters as lipid droplets to protect cells from the toxicity of free intracellular cholesterol [6]. In animals, several researches demonstrated that cholesteryl ester synthesis and ACAT activities in vitro were augmented in the aortic tissues of animals fed with highfat and high-cholesterol diets to induce atherosclerosis [7]. Also, certain ACAT inhibitors exhibited a direct anti-atherosclerotic effect within the arterial wall [8]. Taking together with other results, ACAT is suggested to contribute significantly to the development of foam cell formation in atherosclerosis [3].

In some cholesterol-loaded cells, the cholesterol esterification was increased without changes in ACAT1 mRNA or protein expression levels, but with an increase of ACAT activity $[9,10]$. In vitro studies of ACAT1 supported the hypothesis that the sterol-specific regulation of ACAT1 was mainly happened at the posttranslational level, involving allosteric regulation by its substrate cholesterol [11]. However, ACAT 1 could also be regulated at the transcriptional level. In human macrophages, ACAT1 mRNA expression increased significantly during the differentiation of monocytes into macrophages [12]. Dexamethasone (Dex) treatment also promoted accumulation of cholesteryl esters in human macrophages [13]. Interferon- $\gamma$, a cytokine that exerts a number of pro-atherosclerotic effects in vivo, caused up-regulation of ACAT1 mRNA in mouse macrophages, human blood monocyte-derived macrophages and macrophage-like cells, but not in other cell types [14]. Yang et al showed that in monocytic THP-1 cells, the combination of IFN- $\gamma$ and all-trans-retinoic acid (ATRA) enhanced the ACAT1 gene P1 promoter activity in a synergistic manner [15].

In the current work, the effect of Dex on the ox-LDLinduced foam cell formation and the molecular mechanism of cellular cholesteryl ester accumulation were investigated. Our results indicated that Dex promoted the macrophage-derived foam cell formation in both quantity and extent at lower ox-LDL concentration, enhanced human ACAT1 expression both in mRNA and protein levels, and increased the activity of human ACAT1 gene P1 promoter in a cell-specific manner. Further experimental evidences showed that a glucocorticoid response element (GRE) located within human ACAT1 gene P1 promoter to response to the elevation of ACAT1 gene expression by Dex could be functionally bound with glucocorticoid receptor (GR).

\section{MATERIALS AND METHODS}

\section{Reagents}

Cell culture reagents and T4 DNA ligase were purchased from Life Technologies (Rockville, MD, USA). All the restriction enzymes and agarose were from Promega (Madison, WI, USA). Taq DNA polymerase and dNTPs were from Sino-American Biotech (Shanghai, China). All the oligonucleotides were synthesized with an automated
DNA synthesizer in Institute of Biochemistry and Cell Biology, Shanghai Institutes for Biological Sciences, Chinese Academy of Sciences. Dexmathasone (Dex), phorbol myristate acetate (PMA), human low density lipoprotein (LDL), and lipoprotein-deficient fetal bovine serum (LD-FBS) were from Sigma (St. Louis, MO, USA). To oxidize LDL, human LDL was incubated with $20 \mu \mathrm{M} \mathrm{CuSO}_{4}$ at $37^{\circ} \mathrm{C}$ for $24 \mathrm{~h}$ [16]. Goat anti-rabbit IgG, ECL detection reagent, and anti-GR antibody were from Santa Cruz Biotechnology (Santa Cruz, CA, USA). The nucleotide oligomers were synthesized with an automated DNA synthesizer in Institute of Biochemistry and Cell Biology, Shanghai Institutes for Biological Sciences, Chinese Academy of Sciences.

\section{Cell culture}

All cell lines were maintained in a basal medium as indicated, supplemented with $10 \%$ fetal bovine serum (FBS), $100 \mu \mathrm{g} / \mathrm{ml}$ kanamycin, $50 \mathrm{U} / \mathrm{ml}$ streptomycin at $37^{\circ} \mathrm{C}$ in a humid atmosphere of 95\% air and 5\% $\mathrm{CO}_{2}$. Monocytic THP-1 cells, kindly provided from Dr. Roger Newton, formerly (scientist) of Parke-Davis Pharmaceuticals (Ann-Arbor, MI), were grown in RPMI 1640 medium. To trigger differentiation into macrophage-like cells $[17,18]$, THP-1 cells were seeded at a density of $2 \times 10^{6}$ cells per $60 \mathrm{~mm}$ dish and were grown in $5 \mathrm{ml}$ of RPMI 1640 medium containing 10\% FBS and PMA $(0.1 \mu \mathrm{M})$ for $2 \mathrm{~d}$. HepG2 and HEK293 cells were obtained from American Type Culture Collection (Rockwell, MD, USA). HepG2 cells were grown in DMEM medium and HEK293 cells were grown in MEM medium.

\section{Lipid staining}

THP- 1 cells $\left(1 \times 10^{6}\right)$ were grown on cover slips in a 12-well plate with RPMI 1640 supplemented with $10 \%$ FBS and PMA $(0.1 \mu \mathrm{M})$ for $48 \mathrm{~h}$ at $37^{\circ} \mathrm{C}$ to allow for differentiation into macrophages $[17,18]$. Differentiated THP-1-derived macrophages were then treated with various concentrations of ox-LDL with or without ACAT1 inhibitor in RPMI 1640 containing 10\% LD-FBS and $0.1 \mu \mathrm{M}$ of PMA, in presence or absence of $1 \mu \mathrm{M}$ of Dex for $48 \mathrm{~h}$. The cells were fixed with $4 \%$ formaldehyde for $20 \mathrm{~min}$, rinsed with water, dipped in $60 \%$ isopro-panol, and stained in oil red $\mathrm{O}$ for $15 \mathrm{~min}$ to identify lipid droplets containing cholesteryl esters. Cell nuclei were then stained in haematoxylin for a few sec. All procedures were performed at room temperature. Lipid droplet accumulation in the foam cells was evaluated by a microscope (Olympus Bx60) and divided into three grades,+++ and +++ , each standing for the intracellular lipid droplets occupied $<1 / 3,1 / 3-2 / 3$, or $>2 / 3$ in cytoplasm. The total cell and foam cell numbers in each grade were counted, and the percentage of foam cells was calculated.

\section{Chimeric constructs}

The previously described wild type ACAT1 gene P1 promoter/ Luc construct [15] containing the $-598 /+34$ region of human ACAT1 gene $\mathrm{P} 1$ promoter was used in this study to define luciferase activity in different cell lines. A fragment of $-562 /+34$ in human ACAT1 gene P1 promoter was achieved by PCR with a fwd. primer $(059 \mathrm{~F}$, 5'AAAGGTACCTTTTATTATTTGGTGCAG3') (italic: Kpn I site) and a rev. primer (063R, 5'AAAGCTAGCGGGCCCGCAACGTC3') with the Nhe I site (italic). After comfired by DNA sequencing, the amplified fragment was then inserted into the Kpn I and Nhe I sites of 
pGL2-E to generate the 5 '-deleted ACAT1 gene P1 promoter/Luc construct, which was further used for luciferase activity assay in different cell lines.

\section{Transfection}

The human ACAT1 gene P1 promoter/Luc constructs were individually transfected into cells using the DEAE-dextran method [15, $19,20]$. Briefly, after washing twice with PBS, $1 \times 10^{6}$ THP- 1 cells were transfected with $1.5 \mu \mathrm{g}$ of human ACAT1 gene P1 promoter/ Luc construct as test sample and $0.75 \mu \mathrm{g}$ of $\beta$-galactosidase expression plasmid pCH1 10 (Pharmacia Biotech) as internal control in $1 \mathrm{ml}$ of transfection reagent ( $25 \mathrm{mM}$ Tris- $\mathrm{HCl}, \mathrm{pH} 7.4,5 \mathrm{mM} \mathrm{KCl}, 0.7 \mathrm{mM}$ $\mathrm{CaCl}_{2}, 137 \mathrm{mM} \mathrm{NaCl}, 0.6 \mathrm{mM} \mathrm{Na} \mathrm{HPO}_{4}, 0.5 \mathrm{mM} \mathrm{MgCl}$ ) containing $150 \mu \mathrm{g}$ of DEAE-dextran. The cells were incubated for $20 \mathrm{~min}$ at $37^{\circ} \mathrm{C}$, washed once with FBS-free RPMI 1640 , then resuspended in $5 \mathrm{ml}$ of fresh RPMI 1640 with $10 \%$ FBS and plated at $2 \times 10^{5}$ cells $/ \mathrm{ml} /$ well in a 24-well plate. Cells were treated with or without Dex $(1 \mu \mathrm{M})$ and/or PMA $(0.1 \mu \mathrm{M})$ for $40 \mathrm{~h}$. HEK293 and HepG2 cells were transfected with human ACAT1 gene P1 promoter/Luc constructs using the methods of calcium phosphate co-precipitation as described by Liu J et al [21]. Briefly, $1 \times 10^{5}$ cells/well cells were maintained in $1 \mathrm{ml}$ of medium in 24-well plates for $24 \mathrm{~h}$ and were changed to fresh medium $2 \mathrm{~h}$ before transfection. For each well, the DNA/calcium phosphate precipitates containing $2 \mu \mathrm{g}$ of human ACAT1 promoter/ Luc constructs and $1 \mu \mathrm{g}$ of $\beta$-galactosidase expression plasmid pCH110 that served as an internal standard of transfection efficiency were added dropwise to the medium and incubated with the cells at $37^{\circ} \mathrm{C}$ for $9 \mathrm{~h}$. Then, the cells were rinsed twice with phosphate-buffered saline (PBS), treated with or without Dex $(1 \mu \mathrm{M})$, and further grown in culture medium for another $40 \mathrm{~h}$.

\section{Luciferase activity assay}

The transfected cells were washed twice with cold PBS and lysed in $200 \mu 1$ of reporter lysis buffer (Promega, Madison, WI, USA), vortexed for $5 \mathrm{sec}$ and spun at $2000 \mathrm{~g}$ for $5 \mathrm{~min}$ at room temperature. $60 \mu \mathrm{l}$ of the cell lysate was mixed with $60 \mu \mathrm{l}$ of luciferase assay buffer (Promega) for luciferase activity measurement in an Auto Lumat BG-P luminometer (MGM Instrument Inc.). For $\beta$-galactosidase activity assay, the luminescent $\beta$-galactosidase detection Kit II (Clontech, Palo Alto, CA, USA) was used.

\section{Reverse transcription-polymerase chain reaction (RT-PCR)}

The total cellular RNA ( $4 \mu \mathrm{g})$ prepared according to the single step acid guanidinium thiocyanate phenol chloroform method (Trizol Regent, Life Technologies, Inc., Grand Island, NY, USA) was annealed with $0.5 \mu \mathrm{g}$ of oligo-dT (18-mer in length) in a total volume of $20 \mu \mathrm{l}$, and the ss-cDNAs were synthesized with $1 \mu \mathrm{l}(200 \mathrm{U})$ of moloney murine leukemia virus (MMLV) reverse transcriptase (Promega) at $37^{\circ} \mathrm{C}$ for $60 \mathrm{~min}$. The $1 \mu \mathrm{l}$ of ss-cDNA products were added to a reaction mixture in a final volume of $50 \mu \mathrm{l}$ containing 10 $\mathrm{mM}$ Tris- $\mathrm{HCl}$ (pH 8.3), $50 \mathrm{mM} \mathrm{KCl}, 1.5 \mathrm{mM} \mathrm{MgCl}_{2}, 0.5 \mathrm{mM}$ of each dNTPs, $0.5 \mathrm{mM}$ of each pair of primers, and $2.5 \mathrm{U}$ of Taq DNA polymerase. The PCR products $(10 \mu \mathrm{l})$ were separated on the agarose gel and quantified by using the UVP Labwork Software (UVP Inc.). The forward/reverse primer sets used were: 5'GAGTCAACGGATTTGGTCG3'/5'GAAGTGGTGGTACCTCTTCC3' for GAPDH cDNA product (a 291-bp fragment); 5'AAAGGAGTCCCTAGAG3'/5'GGATGAGAACTC TTGC3' for human ACAT1
cDNA product (a 558-bp fragment).

\section{Preparation of protein samples and Western blot analysis}

Cell lysates were prepared with lysis buffer (10\% SDS in $50 \mathrm{mM}$ Tris, 1 mM EDTA (pH 7.5), 50 mM DTT and protease inhibitor cocktail from Sigma), incubated at $37^{\circ} \mathrm{C}$ and sheared with a syringe fitted with an 18-gauge needle to homogeneity. Protein concentrations of the cell lysates were determined by a modified Lowry method [22]. The protein samples were then subjected to $12 \%$ sodium dodecyl sulfate-polyacrylamide gel electrophoresis (SDS-PAGE). After gel separation, the proteins were transferred to a nitrocellulose membrane. The membrane was blocked with $5 \%$ milk in TBST at room temperature (50 mM Tris- $\mathrm{HCl}, \mathrm{pH} 7.6,0.15 \mathrm{M} \mathrm{NaCl}$, and $0.05 \%$ Tween-20) for $2 \mathrm{~h}$, incubated with the affinity purified rabbit anti-ACAT 1 antibidy DM10 (23) in 5\% milk-TBST at room temperature for $3 \mathrm{~h}$, and with HRP-conjugated goat anti-rabbit secondary antibody (Pierce, Rockford, IL, USA) for an additional $1 \mathrm{~h}$. After incubation, the membrane was washed extensively with TBST and TBS (50 mM Tris$\mathrm{HCl}, \mathrm{pH} 7.6$ and $0.15 \mathrm{M} \mathrm{NaCl}$ ), respectively. The immunoreactive band was visualized by using ECL detection reagent (Pierce).

\section{Electrophoretic mobility shift assays (EMSAs)}

Nuclear extracts were prepared from the THP-1 or Dex-treated THP-1 cells as previously described [15]. A synthesized DNA fragment relevant to the region of human ACAT1 gene P1 promoter served as the DNA probe. The nucleotide oligomers were synthesized for the wild type cDNA fragment -586 to -569 (5'CTTTTAGTTGTTCCATTATTT3'/5'CTTAAATAATGGAACAACTAA3') with the overhangs (italic) for labeling, which contained the potential GRE (underlined). The DNA probe was prepared by mixing the above synthesized complementary oligomers in a buffer containing $500 \mathrm{mM} \mathrm{NaCl}, 200 \mathrm{mM}$ Tris, $\mathrm{pH} 8.0,10 \mathrm{mM}$ EDTA, heating to $94^{\circ} \mathrm{C}$ for $10 \mathrm{~min}$, and cooling to room temperature. Then the probe was labeled with Klenow enzyme by fill-in incorporation with the nucleotide triphosphates, including $\left[\alpha-{ }^{32} \mathrm{P}\right]$-dATP.

The binding reaction mixtures $(10 \mu \mathrm{l})$ contained $2 \mu \mathrm{l}$ of binding buffer (50 mM Tris-HCl, pH 7.5, $5 \mathrm{mM} \mathrm{MgCl} 2,20 \%$ glycerol, 250 $\mathrm{mM} \mathrm{NaCl}, 2.5 \mathrm{mM}$ EDTA, $0.45 \mu \mathrm{g}$ of poly (dI)-(dC) from Amersham Pharmacia Biotech Inc.) and different amounts of the nuclear extracts. For a competition assay, a 200-fold molar excess of cold probe was added to the reaction. To perform supershift assay, $1 \mu 1$ of anti-GR antibody was added to the reaction. All these reaction mixtures were incubated at $25^{\circ} \mathrm{C}$ for $30 \mathrm{~min}$, followed by adding $0.1 \mathrm{pM}$ of the labeled probe and then incubated at $25^{\circ} \mathrm{C}$ for another $30 \mathrm{~min}$. The samples were size-fractionated on a non-denaturing $4 \%$ acrylamide gel (29:1, mass: mass, acrylamide: $N, N^{\prime}$-methylenebisacrylamide), running at $250 \mathrm{~V}$ for $3 \mathrm{~h}$ in $0.5 \times \mathrm{TBE}$ buffer. The gel was subsequently dried and autoradiographed with PhosphorImager scanning system.

\section{RESULTS}

\section{Effect of Dex on the macrophage-derived foam cell formation}

In macrophages, the accumulation of cholesteryl esters synthesized by ACAT1 resulted in the foam cell formation, a hallmark of early atherosclerotic lesions $[1,2]$. Isolation of foam cells from atherosclerotic plaques was difficult to 

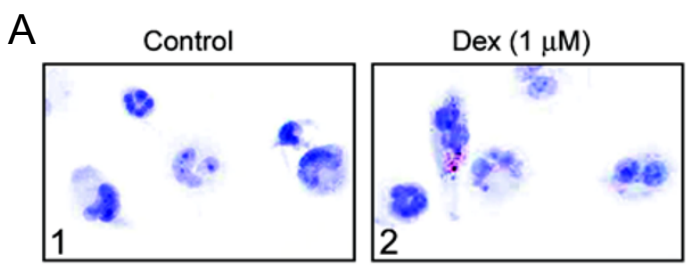

ox-LDL $(20 \mu \mathrm{g} / \mathrm{ml})$
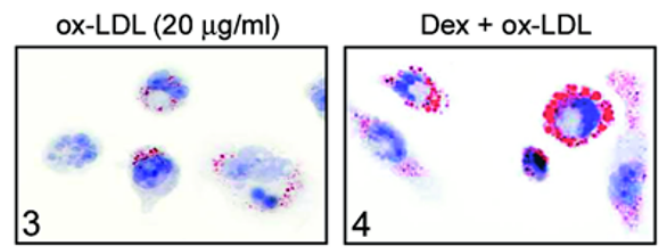

B

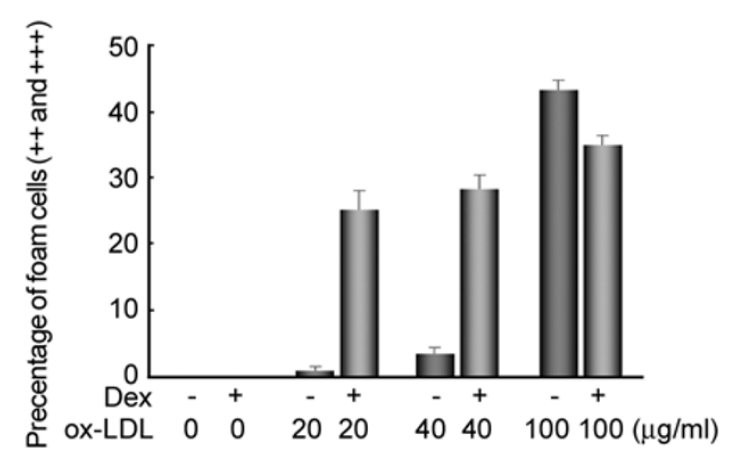

Fig. 1 Macrophage-derived foam cell formation promoted by Dex at lower concentration of ox LDL. The monocytic THP-1 cells were cultured for 2d in RPMI1640 medium containing 10\% FBS and PMA $(0.1 \mu \mathrm{M})$ to induce the differentiation of THP- 1 cells into macrophages, and then incubated in RPMI1640 medium containing $10 \% \mathrm{LD}-\mathrm{FBS}, 0.1 \mu \mathrm{M}$ PMA and various concentrations of ox-LDL with or without treatment of $1 \mu \mathrm{M}$ Dex for $48 \mathrm{~h}$, respectively. The cells were stained with oil red $\mathrm{O}$ and counterstained with Meyer's hematoxylin. (A) Macrophage-derived foam cells were formed at 20 $\mu \mathrm{g} / \mathrm{ml}$ of ox-LDL. Panel 1, the cells treated without Dex and ox-LDL as control. Panel 2, the cells treated with Dex $(1 \mu \mathrm{M})$ alone. Panel 3, the cells treated with ox-LDL $(20 \mu \mathrm{g} / \mathrm{ml})$ alone. Panel 4 , the cells treated with Dex $(1 \mu \mathrm{M})$ plus ox-LDL $(20 \mu \mathrm{g} / \mathrm{ml})$. Original magnification: $\times 1200$. (B) Percentage of foam cells formed at various concentrations of ox-LDL with or without treatment of Dex. The extent of foam cell formation was divided into three grades,+++ and +++ , each standing for the intracellular lipid droplets occupied $<1 / 3$, $1 / 3-2 / 3$, or $>2 / 3$ in cytoplasm, respectively. The percentage of foam cells in ++ and +++ grades was calculated and shown as bars.

perform, so in vitro system of the foam cell formation is very important for studying this change and the relevant molecular mechanism. Using ox-LDL, the macrophagederived foam cell formation was developed as an in vitro model $[24,25]$. In this work, THP-1 cells differentiated into macrophages in vitro induced by the treatment with
A
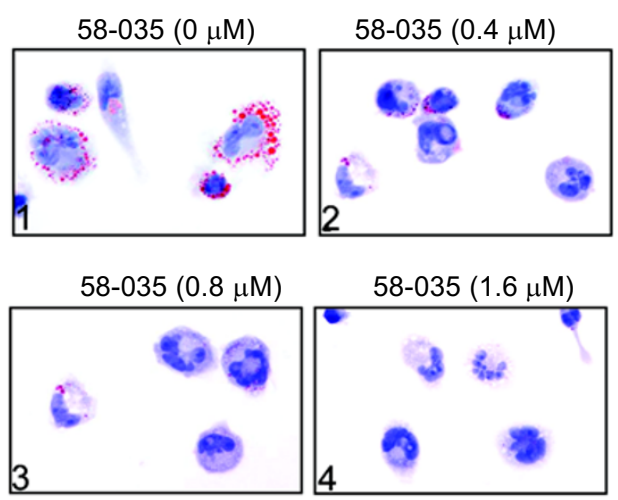

B

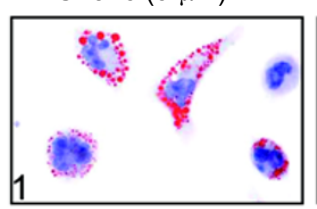

Cl-976 (10 $\mu \mathrm{M})$
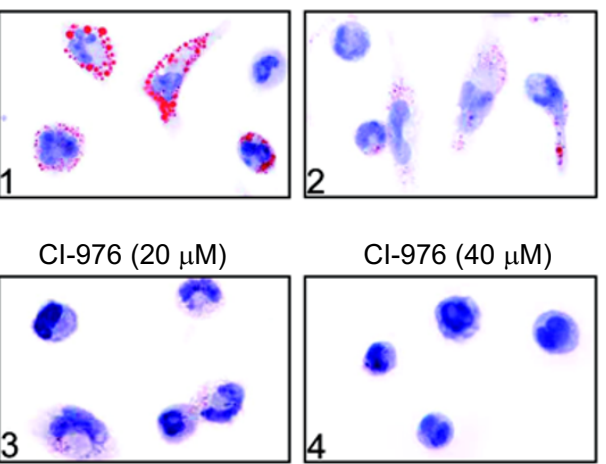

Fig. 2 Effect of ACAT inhibitors on the macrophage-derived foam cell formation. The differentiation of THP-1 cells into macrophages was performed as Fig. 1. The THP-1-derived macrophages were incubated in RPMI1640 medium containing 10\% LD-FBS, $0.1 \mu \mathrm{M}$ PMA and $20 \mu \mathrm{g} / \mathrm{ml}$ of ox-LDL with treatment of $1 \mu \mathrm{M}$ Dex plus various concentrations of ACAT 1 inhibitor for $48 \mathrm{~h}$, then cells were stained as Fig. 1. Original magnification: $x$ 1200. (A) Panels 1-4 were respectively treated with the $0.0,0.4,0.8$ and $1.6 \mu \mathrm{M}$ of ACAT1 inhibitor 58-035. (B) Panels 1-4 were respectively treated with the $0,10,20$ and $40 \mu \mathrm{M}$ of ACAT1 inhibitor CI-976.

PMA [17, 18], and the monocyte (THP-1)-derived macrophages in RPMI 1640 supplemented with the lipoprotein-deficient FBS (LD-FBS) were incubated with various concentrations of ox-LDL for $48 \mathrm{~h}$, in presence or absence of Dex. It was observed that high concentration $(100 \mu \mathrm{g} / \mathrm{ml})$ of ox-LDL could significantly induce the foam cell formation consistent with previous reports [24, 25]. The treatment of either Dex or lower concentration of oxLDL alone had no obvious effect on promoting the macrophage-derived foam cell formation (Fig. 1A, Panel 2 with $1 \mu \mathrm{M}$ of Dex or Panel 3 with $20 \mu \mathrm{g} / \mathrm{ml}$ of ox-LDL alone; Fig. $1 \mathrm{~B}$, with 20 or $40 \mu \mathrm{g} / \mathrm{ml}$ of ox-LDL alone). However interestingly, when the THP-1-derived macrophages were exposed to combined treatment of lower concentrations 

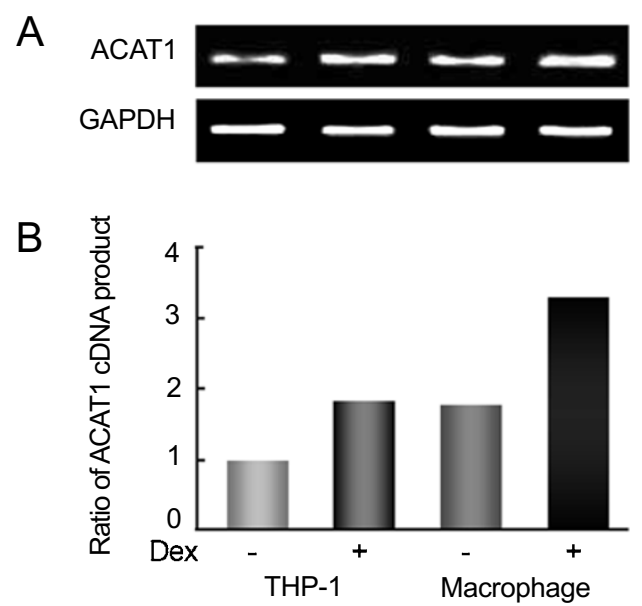

Fig. 3 RT-PCR analysis of human ACAT1 mRNAs from THP-1 cells and THP-1-derived macrophages. Total RNA samples were prepared from THP-1 and THP-1-derived macrophages treated with $(+)$ or without (-) Dex $(1 \mu \mathrm{M})$. The human ACAT1 mRNAs were estimated semi-quantitatively by RT-PCR with the appropriate primer sets described under "Materials and Methods". RT-PCR products were separated on agarose gel and the DNA contents in (A) were determined with UVP Labwork soft ware (UVP. Inc.). By normalizing the contents of the ACAT1 cDNAs in the top panel to the relevant control GAPDH cDNAs in the bottom panel in (A), the ratios of DNAs were exhibited in (B), and that of the ACAT1 cDNAs in THP-1 cells without treatment was set to 1 . The experiments were repeated more than three times with similar results.

(20 and $40 \mu \mathrm{g} / \mathrm{ml}$ ) of ox-LDL and Dex, the huge amounts of oil red $\mathrm{O}$ stained lipid droplets were visible in macrophage-derived foam cells (Fig. 1A, Panel 4) and the macrophage-derived foam cell formation dramatically increase to near $30 \%$ of cells at the "++"/“+++" grades (Fig. 1B). These results demonstrated that Dex $(1 \mu \mathrm{M})$ could markedly promote the macrophage-derived foam cell formation both in quantity and extent at lower ox-LDL concentrations. This promoting effect could be also observed with treatment of various concentrations of Dex (data not shown). However, when incubated at high ox-LDL concentration $(100 \mu \mathrm{g} / \mathrm{ml})$ the effect of Dex on promoting the macrophage-derived foam cell formation could not be observed due to the already high extents of the macrophagederived foam cell formation, about $40 \%$ of cells reached to the " ++""/“+++" grades (Fig. 1B)

Further results showed that by the treatment of Dex together with ACAT inhibitors 58-035 (Fig. 2A) or CI-976 (Fig. 2B), the lipid droplets containing cholesteryl esters was obviously reduced in the THP-1-derived macrophages, indicating that the foam cell formation promoted by Dex at lower concentration of ox-LDL was a result of the enhanced ACAT activity or expression.

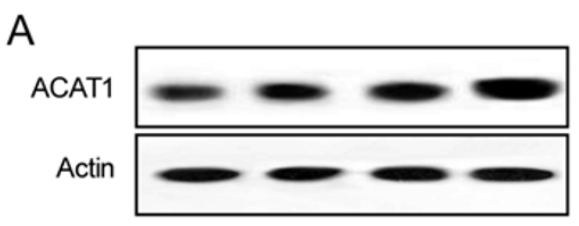

$\mathrm{B}$

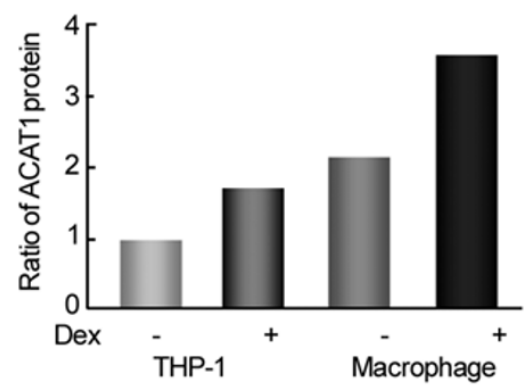

Fig. 4 Western blot analysis of human ACAT1 proteins from THP1 and THP-1-derived macrophages. The cell-lysated protein samples were freshly prepared from THP-1 cells and THP-1-derived macrophages treated with $(+)$ or without $(-)$ Dex $(1 \mu \mathrm{M})$, and separated on $12 \%$ SDS-PAGE (100 $\mu$ g proteins/lane), followed by transferring to the nitrocellulose membranes. The transferred-membranes were respectively incubated with the specific anti-ACAT1 antibody DM10 in the final concentration of $0.5 \mu \mathrm{g} / \mathrm{ml}$. The protein contents in (A) were determined with UVP Labwork soft ware (UVP. Inc.). The ratios of ACAT1 proteins in different cells were exhibited in $(\mathbf{B})$, and that of ACAT1 protein in THP-1 cells without treatment was set to 1 . The experiments were repeated twice with similar results.

\section{Up-regulation of human ACAT1 gene expression in THP-1 cells and THP-1-derived macrophages by Dex}

It has been reported that two ACAT gene-encoding proteins (named ACAT1 and ACAT2) exist in mammals, and ACAT 1 shows the major ACAT activity in macrophages $[4,5]$. Dex is a kind of steroid drugs widely applied to treat a number of medical problems, including several inflammatory diseases [26]. However, there is little information regarding to the enhancement of ACAT1 expression by Dex during the formation of macrophage-derived foam cells. In this study, RT-PCR and Western blot were used to analyze ACAT1 expression in THP-1 cells and THP-1-derived macrophages with the treatment of Dex. The results showed that both the ACAT1 mRNAs (Fig. 3) and proteins (Fig. 4) were increased in the Dex-treated cells, indicating that Dex could up-regulate the ACAT1 expression in both THP-1 and THP-1-derived macrophages. In addition, this up-regulation of the ACAT1 expression by the treatment of Dex was supported in another monocytic cell line U937 (data not shown). These results suggested that the Dex-mediated enhancement of ACAT1 expression might act principally at the 


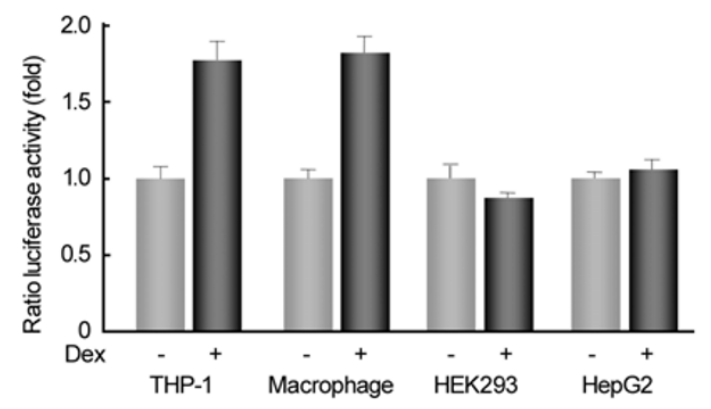

Fig. 5 Lucferase reporter assay for human ACAT1 gene promoter activity. The Luc construct containing ACAT1 gene P1 promoter was individually transfected into THP-1, HEK293, HepG2 cells. Seven hours after transfection, THP-1 cells were treated with PMA $(0.1 \mu \mathrm{M})$ to induce differentiation into macrophages. THP-1, macrophage, HEK293 and HepG2 cells were treated with $(+)$ or without (-) Dex $(1 \mu \mathrm{M})$ respectively. The cells were harvested $40 \mathrm{~h}$ after transfection for luciferase activity assays. The relative luciferase activities were normalized respectively by using $\beta$-galactosidase values measured in the same cell extracts as the internal control. Data were represented as mean $\pm \mathrm{SD}$ of triplicate wells from three independent experiments. The mean values from untreated cells were designated as 1 .

transcriptional level.

\section{Elevation of human ACAT1 gene P1 promoter activity by Dex}

Previous studies have demonstrated the structure of human ACAT1 gene and its P1 promoter region from -598 to $+34[15,27]$. In present work, the effect of Dex on human ACAT1 gene P1 promoter, which plays a major role in ACAT1 activation, was detected in the different cell lines transfected with wild type human ACAT1 gene P1 promoter/Luc construct [15] as test sample and plasmid pSV- $\beta$ Gal as internal control. The transfected THP-1, THP-1-derived macrophage, HEK293 and HepG2 cells were treated with $(+)$ or without (-) Dex, respectively. The luciferase activity assay results showed that the activity of human ACAT1 gene P1 promoter could be upregulated by Dex in both THP-1 cells and THP-1-derived macrophages, but not in HEK293 or HepG2 cells (Fig. 5). Similar results were also seen in another monocytic cell line U937 and U937-derived macrophages (data not shown), indicating that Dex enhanced human ACAT1 gene P1 promoter activity in a cell-specific manner.

As a kind of glucocorticoid, Dex can bind to GR, a nuclear transcription factor, and thus regulate the expression of those genes containing the glucocorticoid response elements (GREs) at their promoters [28]. By using AliBaba2 Data Base, computer analysis showed a potential GRE, TGTTCCATTA (Fig. 6A, boxed, -581/-572) is within human ACAT1 gene P1 promoter. The further results of luciferase activity assay with the wild type $(-598 /+34)$ or 5 '-deleted $(-562 /+34)$ human ACAT1 gene P1 promoter/ Luc constructs (Fig. 6B and 6C, left panel) demonstrated that the deleted region $(-598 /-563)$ containing the potential GRE (-581/-572) was responsible to enhance human ACAT1 gene P1 promoter activity by Dex in both THP-1 cells (Fig. 6B, right panel) and THP-1-derived macrophages (Fig. 6C, right panel). It was found that the potential GRE at human ACAT1 gene P1 promoter contained half of consensus GRE sequence GGTACAnnnTGTTCT (n can be any nucleotide of A, G, C, or T), but could be used as a functional GRE as previously reported [29]. To verify the binding of GR to this potential GRE, electrophoresis mobility shift assays (EMSA) were carried out by using a labeled probe (Fig. 6D, left panel) relevant to the -586 to 569 bp region of human ACAT1 gene P1 promoter. Various amounts of the nuclear extracts of THP-1 cells (Fig. 6D, lanes 2, 6 and 10) or Dex-treated THP-1 cells (Fig. 6D, lanes 3-5, 7-9, and 11-13) were tested. As shown in Fig. 6D, the specific DNA-protein bands were observed with the nuclear extracts from either THP-1 cells (lanes 2, 6, and 10) or Dex-treated THP-1 cells (lanes 3, 7, and 11), by comparing to those of adding 200-fold excess of the unlabeled cold probe (lanes 4,8 , and 12) and gradually increasing amounts of the nuclear extracts $(6,9$ and $12 \mu \mathrm{g}$, respectively). It was clear that the amounts of the specific DNA-protein bands with the nuclear extracts from Dextreated THP-1 cells (Fig. 6D, lanes 3, 7, and 11) were significantly higher than those with the nuclear extracts from THP-1 cells (Fig. 6D, lanes 2, 6, and 10). Gel supershift assays illustrated that the supershift bound bands (S indicated) could be formed by using anti-GR antibody (Fig. 6D, lanes 5, 9, and 13), and the relevant GR-bound bands and complexes (arrowheads indicated) were observed in the lanes 2, 3, 6, 7, 10 and 11 of Fig. 6D, compared to the supershift bound bands. Also, the similar EMSA results were obtained by using the nuclear extracts from either THP-1-derived macrophages or Dex-treated THP-1-derived macrophages (data not shown).

Taken together, nucleotide sequence analysis, luciferase reporter assays, and EMSA showed that the cell-specific activity of human ACAT1 gene P1 promoter might be mediated by the GR-Dex complexe bounding to the functional GRE at the -581 to -572 bp of human ACAT1 gene $\mathrm{P} 1$ promoter region, indicating that the GR-Dex complex was functionally important for human ACAT1 gene expression.

\section{DISCUSSION}

In mammalian cells, the homeostasis of free cholesterol and cholesteryl ester is strictly controlled. However, the 
A

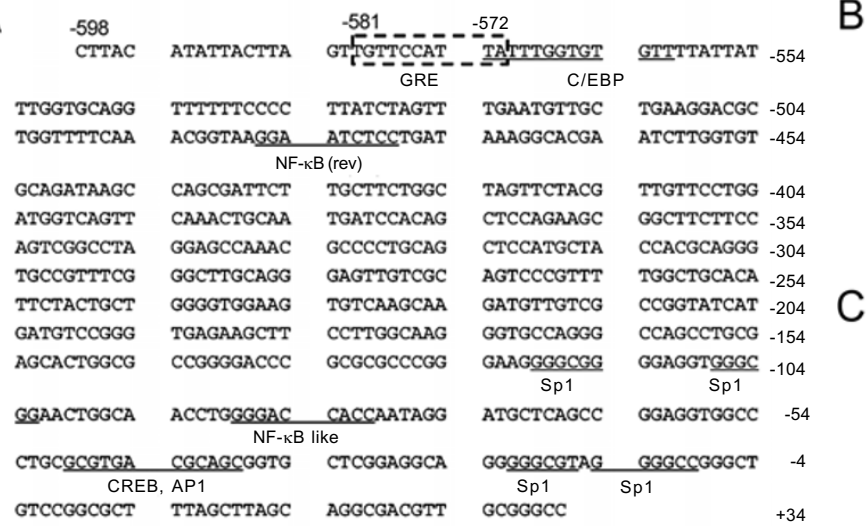

B

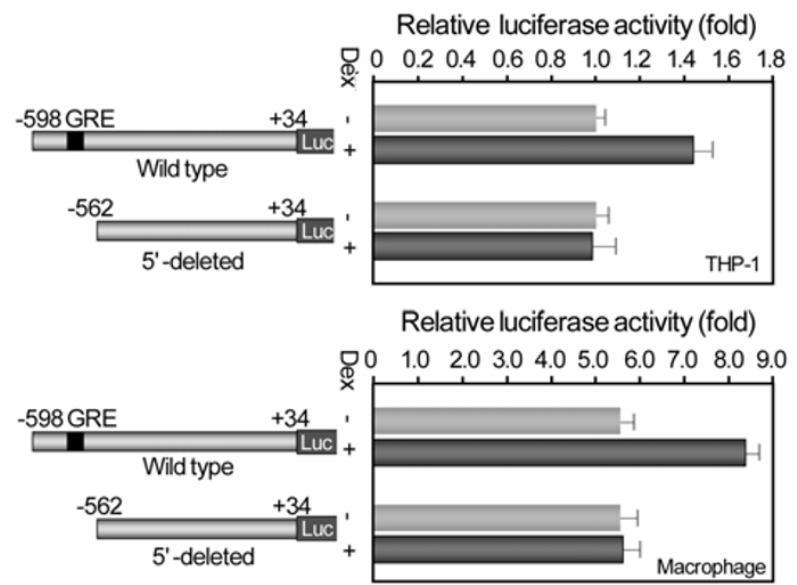

D

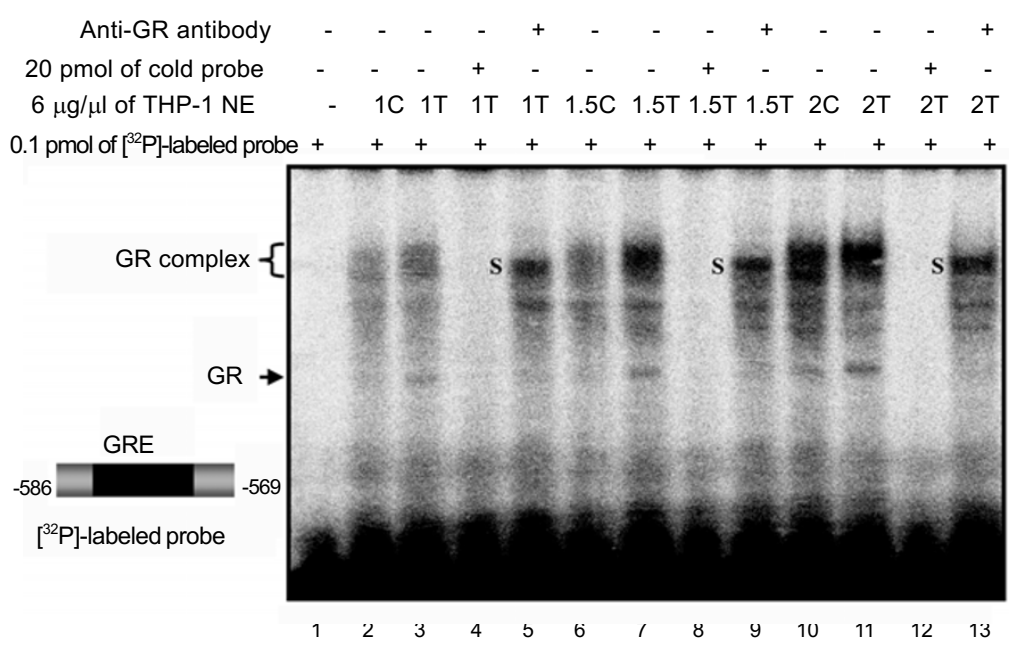

Fig. 6 Analysis of Dex-affected region at human ACAT1 gene promoter. (A) Sequence of human ACAT1 gene promoter was from -598 to +34 , and a potential GRE was boxed and some other potential elements were underlined. (B) and (C) The Luc construct containing the wild type or 5'-deleted human ACAT1 gene P1 promoter ligated to the luciferase reporter vector was transfected into THP-1 cells or THP-1derived macrophages. Seven hours after transfection, cells were treated with or without Dex $(1 \mu \mathrm{M})$. The luciferase activity was determined in cell lysates after $40 \mathrm{~h}$, and normalized by using values of $\beta$-galactosidase. Data were respresented as mean \pm SD values of triplicate wells from three independent experiments. The mean values from untreated THP-1 cells transfected with Luc construct containing the wild type human ACAT1 gene P1 promoter was designated as 1. (D) EMSA for binding between GR and the element at human ACAT1 gene P1 promoter. The $\left[{ }^{32} \mathrm{P}\right]$-labeled probe (left panel) was made by using the synthesized DNA fragment relevant to the -586 to -569 bp region of human ACAT1 gene P1 promoter, which contained the predicated GRE as indicated with the black rectangles. The nuclear extract $(6 \mu \mathrm{g} / \mathrm{ml})$ indicated as $\mathrm{C}$ or T was prepared from THP-1 cells treated without or with Dex $(1 \mu \mathrm{M})$. Each binding reaction was performed as indicated in the top note and with the $\left[{ }^{32} \mathrm{P}\right]$-labeled probe in the left panel. Lane $\left.1,{ }^{32} \mathrm{P}\right]$-labeled probe; Lane 2 or 3, binding reaction between the $0.1 \mathrm{pmol}$ of labeled probe and $1 \mu \mathrm{l}(6 \mu \mathrm{g})$ of the nuclear extract $1 \mathrm{C}$ or $1 \mathrm{~T}$; Lane 4 , competition by adding 200 -fold molar excess of the relevant cold probe to the binding reaction described as lane 3; Lane 5, supershift reaction by adding $1 \mu \mathrm{l}(2 \mu \mathrm{g})$ of the anti-GR antibody to the binding reaction described as lane 3; Lanes 6-9 or 10-13, the performance was the same as lanes 2-5 except by using different amount of the nuclear extract $1.5 \mathrm{C} / 1.5 \mathrm{~T}$ $(9 \mu \mathrm{g})$ or $2 \mathrm{C} / 2 \mathrm{~T}(12 \mu \mathrm{g})$; S, the observed supershift bound bands in lanes 4,8 or 12 . Arrowheads indicated the GR-bound bands and complexes. The experiments were repeated twice with similar results.

homeostasis was disordered in macrophages during the process of atherosclerosis [1]. Consequently, lipid-laden foam cells derived from macrophages are formed, which is a hallmark of early atherosclerotic lesions [2]. Here, we showed that Dex $(1 \mu \mathrm{M})$ could promote the foam cell formation derived from macrophages in vitro, by increas- ing the accumulation of lipid droplets in macrophages at lower ox-LDL concentration. Actually, this promoting effect could be also observed with treatment of various concentrations of Dex (data not shown). Further results showed that Dex caused a up-regulation of human ACAT1 gene expression by enhancing the activity of human ACAT1 
gene P1 promoter, which was a major factor leading to the activated ACAT1 to promote the formation of foam cells from the THP-1-derived macrophages. A Dex-affected region containing a glucocorticoid response element (GRE) was identified in human ACAT1 gene P1 promoter, meaning that the up-regulation of human ACAT1 gene expression by Dex might occur at the transcriptional level through GRE.

During the development of atherosclerosis, chemically modified LDL, but not native LDL, is able to induce the formation of foam cells, and LDL oxidation is likely to be the most important form of modified LDL in human and in circulating human plasma [30]. However, the modified structures, distribution, and metabolism of ox-LDL present in vivo are poorly understood. Accumulating evidences had demonstrated that foam cells were formed from macrophages in vitro at high concentration $(80-160 \mu \mathrm{g} / \mathrm{ml})$ of ox-LDL [24, 25]. Moreover, our results demonstrated that Dex $(1 \mu \mathrm{M})$ could promote the macrophage-derived foam cell formation at lower concentration of ox-LDL in vitro. It has also been reported that Dex increased the formation of cholesteryl esters in human smooth muscle cells and macrophages in a dose-dependent manner [13,31]. Thus, the accumulation of lipid droplets appeared by lipid staining might mainly be caused by the increased cholesteryl esters during the formation of foam cells from the THP-1derived macrophages, with the combined treatment of Dex and lower concentration of ox-LDL.

ACAT is the key enzyme responsible for intracellular cholesterol esterification to maintain the cellular cholesterol homeostasis [3]. Therefore, we examined if Dex could regulate the ACAT1 gene expression or not. Results showed that Dex could enhance the human ACAT1 gene expression at both the mRNA and protein levels in THP-1 and THP-1-derived macrophages. Dex also up-regulated the activity of human ACAT1 gene P1 promoter in THP-1 and THP-1 derived macrophages, but not in other tested cells. The action of Glucocorticoid hormone on cholesterol homeostasis might be mediated in several ways, including enhancement of cholesterol esterification, partial inhibition of cholesteryl ester hydrolysis and redistribution of cholesterol [32]. Our finding that Dex could promote the foam cell formation at lower ox-LDL concentration might be partily caused by the up-regulation of ACAT1 gene expression at the transcriptional level and the enhancement of cholesterol esterification. Our study provides the experimental evidence for understanding that Dex in clinical treatment accelerated or exacerbated the development of atherosclerosis [33, 34].

Activation of GR by Dex is a multi-step process that involves the ability of the receptor to recognize and bind to Dex, undergo a Dex-dependent structural transformation, translocate into the nucleus, and identify target genes by binding to GRE [28]. Additionally, GR can function at three levels: recruitment of the general transcription machinery; modulation of transcription factor action, independent of DNA binding, through direct protein-protein interactions; and modulation of chromatin structure to allow the assembly of other gene regulatory proteins and/or the general transcription machinery on the DNA $[28,35,36]$. In this study, sequence deletion analysis and EMSA indicated that there was a functional GRE at human ACAT1 gene P1 promoter and the GR-Dex complexes could bind to this element to modulate the human ACAT1 gene P1 promoter activity. Through this way, Dex up-regulated the human ACAT1 gene expression to accelerate the cholesteryl ester synthesis in macrophages, thus promoted the foam cell formation. As a hormone-like ligand, Dex plays a role in the transcriptional regulation of human ACAT1 gene. The elaborate molecular mechanism(s) for Dex-enhanced human ACAT1 gene expression remains to be elucidated.

This work demonstrated that Dex could promote the foam cell formation at lower concentration of ox-LDL in vitro by enhancing the human ACAT1 gene expression, and might serve to explain the increasing incidence of atherosclerosis in the clinical treatment with Dex.

\section{ACKNOWLEDGEMENTS}

We thank our colleagues Han Hui MA, Yi WANG for helpful discussion and technical assistance during the course of this study. We also gratefully acknowledge Dr. Catherine CY CHANG for reviewing and discussion in preparing this manuscript. This work was supported by grants of the Major State Basic Research Development program of China (No. 2002CB513000) and National Scienses Foudation Center (N0. 30393110), State Science and Technology Committee (SSTC) (N0.02DJ14068) and Chinese Academy of Science to Bo Liang LI, and NIH grant HL36709 to Ta Yuan CHANG.

Received, Jan 19, 2004

Revised, June 31, 2004

Accepted, July 5, 2004

\section{REFERENCE}

1 Glass CK, Witztum JL. Atherosclerosis: The Road Ahead. Cell 2001; 104:503-16.

2 Libby P. Inflammation in atherosclerosis. Nature 2002; 420:868-74.

3 Chang TY, Chang CCY, Cheng D. Acyl-coenzyme A: cholesterol acyltransferase. Annu Rev Biochem 1997; 66:613-38.

4 Joyce C, Skinner K, Anderson RA, Rudel LL. Acyl-coenzyme A: cholesteryl acyltransferase 2. Curr Opin Lipidol 1999; 10:89-95.

5 Lee O, Chang CC, Lee W, Chang TY. Immunodepletion experiments suggest that acyl-coenzyme A:cholesterol acyltransferase1 (ACAT1) protein plays a major catalytic role in adult human 
liver, adrenal gland, macrophages, and kidney, but not in intestines. J Lipid Res 1998; 39:1722-7.

6 Warner GJ, Stoudt G, Bamberger M, Johnson WJ, Rothblat GH. Cell toxicity induced by inhibition of acyl coenzyme A:cholesterol acyltransferase and accumulation of unesterified cholesterol. J Biol Chem 1995; 270:5772-8.

7 Hashimoto S, Dayton S. Studies of the mechanism of augmented synthesis of cholesteryl ester in atherosclerotic rabbit aortic microsomes. Atherosclerosis 1977; 28:447-52

8 Bocan TM, Mueller SB, Uhlendorf PD, Newton RS, Krause BR. Comparison of CI-976, an ACAT inhibitor, and selected lipid-lowering agents for antiatherosclerotic activity in iliac-femoral and thoracic aortic lesions. A biochemical, morphological, and morphometric evaluation. Arterioscler Thromb 1991; 11:1830-43

9 Matsuda H, Hakamata H, Miyazaki A, et al. Activation of acylcoenzyme A:cholesterol acyltransferase activity by cholesterol is not due to altered mRNA levels in HepG2 cells. Biochim Biophys Acta 1996; 1301:76-84.

10 Rea TJ, DeMattos RB, Homan R, Newton RS, Pape ME. Lack of correlation between ACAT mRNA expression and cholesterol esterification in primary liver cells. Biochim Biophys Acta 1996; 1299:67-74.

$11 \mathrm{Yu}$ C, Chen J, Lin S, et al. Human acyl-CoA: cholesterol acyltransferase-1 is a homotetrameric enzyme in intact cells and in vitro. J Biol Chem 1999; 274:36139-45.

12 Wang H, Germain SJ, Benfield PP, Gillies PJ. Gene expression of acyl-coenzyme-A:cholesterol-acyltransferase is upregulated in human monocytes during differentiation and foam cell formation. Arterioscler Thromb Vasc Biol 1996; 16:809-14.

13 Cheng W, Kvilekval KV, Abumrad NA. Dexamethasone enhances accumulation of cholesteryl esters by human macrophages. Am J Physiol 1995; 269:642-8.

14 Panousis CG, Zuckerman SH. Regulation of cholesterol distribution in macrophage-derived foam cells by interferon-gamma. J Lipid Res 2000; 41:75-83.

15 Yang JB, Duan ZJ, Yao W, et al. Synergistic transcriptional activation of human ACAT1 gene by IFN-gamma and ATRA in THP-1 cells. J Biol Chem 2001; 276:20989-98.

16 Yancey PG, Jerome WG. Lysosomal sequestration of free and esterified cholesterol from oxidized low density lipoprotein in macrophages of different species. J Lipid Res 1998; 39:1349-61.

17 Tsuchiya S, Yamabe M, Yamaguchi Y, et al. Establishment and characterization of a human acute monocytic leukemia cell line (THP-1). Int J Cancer 1980; 26:171-6.

18 Auwerx J. The human leukemia cell line, THP-1: a multifacetted model for the study of monocyte-macrophage differentiation. Experientia 1991; 47:22-31

19 Powell JT, Klaasse Bos JM, van Mourik JA. The uptake and expression of the factor VIII and reporter genes by vascular cells. FEBS Lett 1992; 303:173-7.

20 Mack KD, Wei R, Elbagarri A, Abbey N, McGrath MS. A novel method for DEAE-dextran mediated transfection of adherent primary cultured human macrophages. J Immunol Methods 1998;
211:79-86.

21 Liu J, Streiff R, Zhang YL, et al. Novel mechanism of transcriptional activation of hepatic LDL receptor by oncostatin M. J Lipid Res 1997; 38:2035-48.

22 Peterson GL. A simplification of the protein assay method of Lowry et al which is more generally applicable. Anal Biochem 1977; 83:346-56.

23 Chang CCY, Chen J, Thomas MA, et al. Regulation and immunolocalization of acyl-coenzyme A: cholesterol acyltransferase in mammalian cells as studied with specific antibodies. J Biol Chem 1995; 270:29532-40.

24 Klinkner AM, Waites CR, Kerns WD, Bugelski PJ. Evidence of foam cell and cholesterol crystal formation in macrophages incubated with oxidized LDL by fluorescence and electron microscopy. J Histochem Cytochem 1995; 43:1071-8.

25 Greenspan P, Yu H, Mao F, Gutman RL. Cholesterol deposition in macrophages: foam cell formation mediated by cholesterolenriched oxidized low density lipoprotein. J Lipid Res 1997; 38: 101-9.

26 Jan DG, Diederik van DB. Dexamethasone in adults with bacterial meningitis. N Engl J Med. 2002; 347:1549-56.

27 Li BL, Li XL, Duan ZJ, et al. Human acyl-CoA: cholesterol acyltransferase-1 (ACAT1) gene organization and evidence that the 4.3-kilobase ACAT1 mRNA is produced from two different chromosomes. J Biol Chem 1999; 274:11060-71.

28 McEwan IJ, Wright AP, Gustafsson JA. Mechanism of gene expression by the glucocorticoid receptor: role of protein-protein interactions. Bioessays 1997; 19:153-60.

29 Morin B, Zhu C, Woodcock GR, et al. The Binding Site for Xenopus Glucocorticoid Receptor Accessory Factor and a Single Adjacent Half-GRE Form an Independent Glucocorticoid Response Unit. Biochemistry 2000; 39:12234-42.

30 Itabe $\mathrm{H}$, Takano T. Oxidized low density lipoprotein: the occurrence and metabolism in circulation and in foam cells. J Atheroscler Thromb 2000; 7:123-31.

31 Igor EP, Daniele D, Galina VK, Yuri AS, Jacky L. Glucocorticoids stimulate chlesteryl ester formation in human smooth muscle cells. Arterioscler Thromb Vasc Biol 1997; 17:1143-51.

32 Stein O, Stein Y. Dexamethasone impairs cholesterol egress from a localized lipoprotein depot in vivo. Atherosclerosis 1998; 137: 303-10.

33 Kalbak K. Incidence of arteriosclerosis in patients with rheumatoid arthritis receiving long-term corticosteroid therapy. Ann Rheum Dis 1972; 31:196-200.

34 Troxler RG, Sprague EA, Albanese RA, Fuchs R, Thompson AJ. The association of elevated plasma cortisol and early atherosclerosis as demonstrated by coronary angiography. Atherosclerosis 1977; 26:151-62.

35 Herrlich P. Cross-talk between glucocorticoid receptor and AP1. Oncogene 2001; 20:2465-75.

36 Deroo BJ, Archer TK. Glucocorticoid receptor-mediated chromatin remodeling in vivo. Oncogene 2001; 20:3039-46. 